\title{
EDITORIAL
}

\section{Clinical examination or whole-body magnetic resonance imaging: the Holy Grail of spondyloarthritis imaging}

\author{
Winston J Rennie* \\ See related research by Weber et al., http://arthritis-research.com/content/14/1/R3
}

\begin{abstract}
Whole-body magnetic resonance imaging allows acquisition of diagnostic images in the shortest scan time, leading to better patient compliance and artifact-free images. Methods of clinical examination of the anterior chest wall joints vary between physician groups and consideration of the rules of rib motion is suggested. The type of joint and its synovial lining may also aid imaging/clinical correlation. This well-written study by experts in the field with a standardized design and methodology allows good scientific analysis and suggests the advantages of whole-body magnetic resonance imaging in anterior chest wall imaging. Selection of clinical examination criteria and specific joints may have had an influence on the study results and the lack of association reported.
\end{abstract}

The Holy Grail of magnetic resonance imaging (MRI) is the acquisition of diagnostic images in the shortest scan time, leading to better patient compliance and thereby to images without artifacts. The Holy Grail of a scientific study is a standardized design and a methodological approach. The recent study by Weber and colleagues is written by experts in the field who have utilized both these unwritten commandments [1]. They have used a standardized design and methodology in their selection of whole-body MRI. This allows a good scientific analysis of the clinical parameters and imaging in the assessment of anterior chest wall findings in spondyloarthropathy (SpA).

It is arguable, however, that conventional MRI at higher fields, with cardiorespiratory gating, allows a more

*Correspondence: winston.rennie@uhl-tr.nhs.uk

Department of Radiology, Leicester Royal Infirmary, Hospital Square, Leicester LE1 5WW, UK accurate assessment of joints by providing better spatial resolution than whole-body MRI, and the selection of this modality could have led to the inclusion of false positive lesions. The poor specificity and the costeffectiveness of whole-body MRI has led to questioning its value as a screening investigation in the past [2], and this study may help rethink that approach [1].

The selection of an important yet traditionally ignored joint involved in SpA is also intriguing [3]. The morphoanatomy of the costovertebral joint, its involvement in enthesitis and the importance of standardized MRI protocols have been previously stressed [4]. It is not just the imaging of the anterior chest wall joints that needs standardization, but the methods used to clinically examine these joints by different physician groups. The clinical assessment using the Maastricht Ankylosing Spondylitis Enthesitis Score protocol relies on palpation pressure [5]. This protocol does not deal with the rules of rib motion. Ribs 1 to 5 exhibit primarily 'pump-handle motion', whereas ribs 6 to 10 exhibit 'bucket-handle motion' Ribs 11 and 12, which do not articulate with the thoracic cage, undergo 'caliper motion'. The clinical examination of each set of ribs and differing motion requires varying assessment, as is performed by sports physicians [6]. These variations may account for some of the results reported.

Furthermore, the reduction of the Mander Enthesis Index, with the selection of the first and seventh rib joints, in the Maastricht Ankylosing Spondylitis Enthesitis Score may also account for the lack of association found [7]. The first rib is a synchondrosis or a synostosis, with no movement at the anterior joint [8]. To capture the relevant joints, along with varying types of motion, selection of the second and seventh anterior joints may have produced better correlation.

The type of joint and its synovial lining also influences variations in involvement and patterns of inflammation that are seen on imaging. The second costal cartilage and its articulation with the manubrium and the body of the 
sternum is unique in that it has an interarticular ligament and two synovial membranes. This arrangement is similar to the costovertebral joints that demonstrate a characteristic pattern of inflammation on MRI in SpA [9]. The inflammatory patterns may therefore differ, allowing better specificity in SpA.

Whilst stimulating much thought, this well-written study by experts in the field, with its standardized design and methodology, allows a good scientific analysis of findings and suggests the advantages of a relatively new imaging variation. Whole-body MRI with its holistic screening approach may yet help redefine the SpA disease process. The selection of clinical criteria, however, may have had an influence on the study results and the lack of association reported.

Abbreviations

MRI, magnetic resonance imaging; SpA, spondyloarthropathy.

\section{Competing interests}

The author declares that he has no competing interests.

Published: 29 February 2012

\section{References}

1. Weber U, Lambert RGW, Rufibach K, Maksymowych WP, Hodler J, Zejden A, Duewell S, Kissling RO, Filipow PL, Jurik AG: Anterior chest wall inflammation by whole-body magnetic resonance imaging in patients with spondyloarthritis: lack of association between clinical and imaging findings in a cross-sectional study. Arthritis Res Ther 2012, 14:R3.

2. Canadian Health Services Research Foundation: Myth: whole-body screening is an effective way to detect hidden cancers. J Health Serv Res Policy 2010, 15:118-119.

3. Maksymowych WP, Miller C, Velez M, Savage L: To what degree do the BASDAI and BASFI questionnaires address the most essential symptoms and disabilities of patients with ankylosing spondylitis? [Abstract.] Ann Rheum Dis 2007, 66(Suppl II):405.

4. Rennie WJ, Dhillon SS, Conner-Spady B, Maksymowych WP, Lambert RG: Magnetic resonance imaging assessment of spinal inflammation in ankylosing spondylitis: standard clinical protocols may omit inflammatory lesions in thoracic vertebrae. Arthritis Rheum 2009, 61:1187-1193.

5. Mander M, Simpson JM, McLellan A, Walker D, Goodacre JA, Dick WC: Studies with an enthesis index as a method of clinical assessment in ankylosing spondylitis. Ann Rheum Dis 1987, 46:197-202.

6. Karageanes SJ: Principles of Manual Sports Medicine. Philadelphia: Lippincott Williams and Wilkins; 2005:275-276.

7. Heuft-Dorenbosch L, Spoorenberg A, van Tubergen A, Landewe R, van der Tempel H, Mielants H, Dougados M, van der Heijde D: Assessment of enthesitis in ankylosing spondylitis. Ann Rheum Dis 2003, 62:127-132.

8. Maksymowych WP, Lambert RG: Magnetic resonance imaging for spondyloarthritis - avoiding the minefield. J Rheumatol 2007, 34:259-265.

9. Schils JP, Resnick D, Haghigi P, Trudell D, Sartoris DJ: Sternocostal joints. Anatomic, radiographic and pathologic features in adult cadavers. Invest Radiol 1989, 24:596-603.

doi:10.1186/ar3737

Cite this article as: Rennie WJ: Clinical examination or whole-body magnetic resonance imaging: the Holy Grail of spondyloarthritis imaging. Arthritis Research \& Therapy 2012, 14:110. 